\title{
Age dependent switching role of cyclin D1 in breast cancer
}

\author{
Carmela Rinaldi ${ }^{\mathrm{a}}$, Natalia Maria Malara ${ }^{\mathrm{b}}$, Rosalia D’Angelo ${ }^{\mathrm{a}}$, Antonina Sidoti ${ }^{\mathrm{a}, *}$, Attilio Leotta ${ }^{\mathrm{c}}$, \\ Santo Lio $^{\mathrm{c}}$, Basilio Caparello ${ }^{\mathrm{c}}$, Alessia Ruggeri ${ }^{\mathrm{a}}$, Vincenzo Mollace ${ }^{\mathrm{b}}$ and Aldo Amato ${ }^{\mathrm{a}}$ \\ ${ }^{a}$ Faculty of Medicine, Department of Biomorphology and Biotechnologies, Division of Biology and Genetics, \\ University of Messina, Messina, Italy \\ ${ }^{\mathrm{b}}$ Laboratory of Toxicology, Faculty of Pharmacy, Department of Pharmaceutical Science, University of Magna \\ Graecia, Catanzaro, Italy \\ ${ }^{\mathrm{c}}$ Department of Pathology, Lamezia Terme Hospital, Lamezia Terme CZ, Italy
}

Received: July 27, 2011

Accepted: December 5, 2011

\begin{abstract}
Background: Cyclin D1 gene (CCND1) plays pivotal roles in the development of several human cancers, including breast cancer, functioning as an oncogene. The aim of this study was to better understand the molecular dynamics of ductal carcinomas with regard to proliferation and the ageing process.

Methods: 130 cases of ductal breast cancer in postmenopausal women, aged 52-96 in 3 age classes were selected. Tumoral tissues preserved in formaldehyde solution and subsequently embedded in paraffin were subjected to analysis Fluorescence in situ Hybridization (FISH), Reverse Transcription-Polymerase Chain Reaction (RT- PCR) and immuno-histochemical tests. The molecular variables studied were estimated in relation to the patients' age.

Results: The results obtained suggest that the increment of the levels of cyclin D1 in intra-ductal breast tumors in older woman that we have examined is significantly associated with a lower proliferation rate.

Conclusion: Cyclin D1, which characterizes tumor in young women as molecular director involved in strengthening tumoral proliferation mechanisms, may be seen as a potential blocking molecular switch in corresponding tumours in old women.
\end{abstract}

Keywords: CCND1, cyclin D1, breast intra-ductal tumors, cell cycle, older women

\section{Introduction}

Breast cancer is the most frequent malignancy in women and ductal carcinoma in situ (DCIS) of the breast is a heterogeneous disease, clinically and biologically.

Cyclin D1 gene $(C C N D 1)$ encodes the regulatory subunit of a holoenzyme promoting progression through the G1-S phase of the cell cycle in a

\footnotetext{
${ }^{*}$ Corresponding author: Antonina Sidoti, Associated Prof. Department of Biomorphology and Biotechnologies, Division of Biology and Genetics, University of Messina, Messina, Italy. Tel.: +39 090 2213372; Fax: +39 090 2934167; E-mail: antonella.sidoti@unime.it.
}

manner dependent on cyclin-dependent kinases (CDKs). The deduced cyclin D1 protein contains 295 amino acids and has a calculated molecular mass of $33.7 \mathrm{kD}$. Amplification or overexpression of CCND1 plays pivotal roles in the development of several human cancers, including breast cancer, functioning as an oncogene [11-21]. In addition, $C C N D 1$ regulates transcription factors, coactivators and corepressors that govern histone acetylation and chromatin remodeling proteins. The upregulation occurs through several different pathways, including epidermal growth factor receptor (EGFR) family proteins, that act not only as signaling initiators on the cell membrane, but also as nuclear transcriptional cofactors [16]. EGFR associated with the promoter region of $C C N D 1$, activates 
overexpression of cyclin D1, through transcriptional activation of the gene, giving a more aggressive tumor behavior [10].

CCND1 has roles also in cellular growth, metabolism, cellular differentiation and apoptosis. Particularly, deregulation of CCND1 expression is one of the most common genetic aberrations found in malignancies and in actively cycling cells significantly increased also migration [15]. A recent study suggests that $C C N D 1$ overexpression markedly increased the apoptotic response of cells to CDK inhibitors (CDI) in human myeloma cells (U266) [5] often accompanied by cell cycle arrest and down-regulation of nuclear factor kappa B (NF-kappa B) [18-20]. The enhanced expression of cyclin D1 in breast ductal carcinoma is associated also with an increase in both proliferative activity [23] and expression of oestrogen receptors (ER) [3]. The immunohistochemical detection of estrogen (ER) and progesterone (PR) receptors in breast cancer is routinely used for prognostic and predictive testing [13]. The contemporary presence of enhanced cyclin D1 expression, receptor positivity for oestrogens and increased expression of ki-67 antigene, a marker of cellular proliferative activity, was considered as a proliferative axis of the breast ductal carcinoma. Increased cyclin D1 expression may be caused by manifold molecular events [25]: oestrogen hormones, for example, may induce cyclin D1 expression, especially in breast ductal carcinoma in situ and negative erb 1 [14-24]. At the same time, increased cyclin D1 expression, in breast ductal carcinoma in situ, does not automatically lead to increase cellular proliferation [9]. Also the confirmation of CCND1 amplification does not always mean the presence of increased expression, in fact few authors have found a correlation between CCND1 amplification and an increase in the protein [6, 22-27].

Previous studies have shown that an enhanced expression of cyclin D1 in senescent fibroblasts in culture, is not random. It is not clear, however, whether the presence of higher levels of the protein, wich arrests cell growth, is an epiphenomenon or a cause or a consequence of the cell aging process. Studies on senescent cell lines have highlighted how these cells, if stimulated to grow, are suitable for carrying out repetitive events but, on entering the $S$ phase, collapse [7-17]. The mechanism for the collapse of the proliferation may be linked to the reduced expression of genes involved in the initial phase of the process. In senescent cells, the levels of cyclin D1 are increased about seven fold com- pared to normal young cells. The enhanced expression of cyclin D1 also leads to proliferation inhibition [2-8]. Therefore the overexpression of cyclin D1 could be a defense mechanism, which the senescent cell triggers in response to inappropriate stimulation regarding proliferation [28]. The presence of an enhanced expression of cyclin D1 concentration in senescent cell lines is however a signal that this cyclin is involved in the cell ageing process. These data suggest that in aged cells the cyclin D1 overexpression has the function to stop proliferation. The aim of this study is to investigate on the cyclin D1 proliferating role in aging breast cancer cases. We involved a group of old women affected by advanced breast cancer to clarify cyclin D1 role in this particular subset of breast cancer cases.

\section{Materials and methods}

\subsection{Collection of clinical data}

Clinical information was obtained by review of medical records in specific electronic registers Before recruitment, each patient was asked to sign an informed consent form. 130 patients' information included: date of birth, age at diagnosis, age at last menstrual period and number of lymph nodes involved and stage at diagnosis. The median age of these patients was 52-96 years. 104 patients $(80 \%)$ underwent total mastectomy and $26(20 \%)$ breast-conserving surgery. No adjuvant chemotherapy was administered. The size of the breast cancers at diagnosis (according to the criteria of the World Health Organisation) was: pT1-pT2 in 116 cases $(89 \%)$ and pT3-pT4 in 14 cases $(11 \%)$. These cases were classified according to nuclear grading (NG) and necrosis at the time of diagnosis. We have no data on the clinical outcomes of these patients.

Tumoral tissues, obtained after surgery, were preserved in formaldehyde solution for more than 24 hours, and subsequently embedded in paraffin. The slides, on which they were fixed tissue sections of $4 \mu \mathrm{m}$ sections, were coloured with hematoxylin and eosin to identify the most representative areas, which were then pre-treated in preparation for Fluorescence in situ Hybridization (FISH) and immuno-histochemical tests.

$40 \mu \mathrm{m}$ sections of formalin- fixed, paraffin- embedded tumour biopsy samples were identified also to test and validate the gene expression analysis by Reverse Transcription-Polymerase Chain Reaction (RT- PCR). 


\subsection{Immunohistochemical staining}

Our method of performing immunohistochemistry has been reported in literature [7-26].

Briefly, the sections were incubated with the appropriate mouse monoclonal antibodies: Anti-ER Clone 1D5 (DAKO Corporation); Anti-PgR Clone PgR 636 (DAKO Corporation); Anti-ki67 Clone Mb1 (ZYMED), used at dilution rate of $1: 30$; Anticyclin D1 Clone SP4 (NEOMARKERS), used at dilution rate of $1: 100$. Primary antibody detection was accomplished using the DAKO Biotin-Streptavidin Peroxidase Detection Kit. Sections were incubated with biotinylated goat anti-mouse antibody for $10 \mathrm{~min}$ and streptavidin peroxidase for $5 \mathrm{~min}$ with Trisbuffered saline washes between steps.

The diaminobenzidine tetrachloride Substrate Kit was used to visualize the antibody-antigen complex. Appropriate negative controls, consisting of histological sections of each case processed without the addition of primary antibody, were prepared for each antigen retrieval method, along with a positive/negative multitissue control section.

Two independent observers performed a blind analysis. All requisite techniques involved were previously validated and results of scoring were found to be reproducible between the two independent operators, as reported previously [17].

\subsection{Fluorescence in situ hybridization (FISH)}

To determine gene and chromosome copy numbers, levels of gene amplification or deletion in situ, both a locus-specific DNA probe and a chromosome enumeration probe for 11 (site of CCND1 locus $11 \mathrm{q} 13$ and centromere 11) in a dual hybridization reaction were used. Dual-target, dual-colour FISH assays were performed using the Path Vysion Cyclin D1 DNA probe kit (Vysis, Rosedale House, Richmond Surrey, UK), including the LSI Cyclin D1 sequence labelled in Spectrum Orange and the chromosome 11 centromere sequence labelled in Spectrum Green. The probes were applied to $4 \mu \mathrm{m}$ tissue sections of tumour specimens, according to procedure reported previously [17]. Microscopic analysis was performed on an Olympus PROVIS AX70, brightfield and epifluorescence microscope. Fluorescence signals were scored using single-band pass filters for DAPI, FITC, Texas Red. Fuorochrome signals were captured individually and representative images were generated via computer digitization with the CytoVision System and CytoProbe Software.

The evaluation was performed considering the cases with a normal disomic signal pattern for $C C N D 1$, and centromere 11 showed a ratio of gene copy number to centromere copy number $2 / 2$ or $1 / 1$, respectively. Increased copy number was assessed when at least $30 \%$ of nuclei showed increased centromere and/or gene FISH signals.

Amplification was assessed when at least half of these nuclei (15\% of total) showed an unbalanced increase of gene copy numbers (ratio of gene copy number to centromere copy number $\geq 1.5$ ). Genes were considered to be gained (over-presented) with a ratio of $>1.5$ and lost (under-presented) with a ratio of $<1.5$.

\subsection{Total RNA isolation}

RNA was extracted using the RecoverAll TM Total Nucleic Acid Isolation Kit for FFPE Tissues (Applied Biosystems, cat.\# AM1975) [1-19]. First the paraffin was removed from the tissue through a series of washing with ethanol and xylene. Next, it was subjected to a rigorous digestion with Proteinase $\mathrm{K}$ and Digestion Buffer in an incubation time tailored for RNA. Binding Solution and ethanol were added to the lysate and the solution was loaded onto a column. RNA bound to the resin was then washed with Wash Solution to remove any impurities and then eluted with the Elution Buffer.

\subsection{Reverse transcription -polymerase chain reaction $(R T-P C R)$}

Total RNA was converted to cDNA using the High Capacity cDNA Reverse Transcription Kit (Applied Biosystems, cat.\# 4368814) in a $20 \mu \mathrm{L}$ reaction volume containing $3 \mu \mathrm{g}$ of total RNA, 10X RT-PCR buffer, 10U RNase inhibitor, 50U Multiscribe Reverse Transcriptase, 25X mM Dntp mix, 10X Random primer and Nuclease-free $\mathrm{H}_{2} \mathrm{O}$ under the following thermal cycler conditions: $25^{\circ} \mathrm{C}$ for $10 \mathrm{~min}, 37^{\circ} \mathrm{C}$ for $120 \mathrm{~min}, 85^{\circ} \mathrm{C}$ for $5 \mathrm{~min}$ and $4^{\circ} \mathrm{C}$ forever. cDNA is then used in separate PCR assay using $50 \mu \mathrm{l}$ volume containing $5 \mu \mathrm{l}$ of cDNA as template, 2.5 U AmpliTaq Gold DNA Polymerase and $0.2 \mu \mathrm{M}$ of each primer designed by us of mRNA sequences (Accession NCBI NM_053056.2 Table 1). DNA amplification was performed conven- 
Table 1

Oligonucleotide primer sequences used for RT-PCR

\begin{tabular}{lllcccc}
\hline Primer & Forward & Reverse & Length (bp) & Exon & nt & Accession NCBI \\
\hline CCND1 & $5^{\prime}$-tgaactacctggaccgctt-3' & $5^{\prime}$-gatggtctccttcatcttag-3' & 107 & 2 & $445-551$ & NM-053056.2 \\
GAPDH & $5^{\prime}$-aacctgccaaatatgatgac-3' & $5^{\prime}$-actgagtgtggcagggactc-3' & 340 & $8-9$ & $854-1192$ & NM-002046 \\
\hline
\end{tabular}

CCND1: Cyclin D1 gene; GAPDH: glyceraldehyde-3-phosphate dehydrogenase; nt: nucleotides; Length: amplified fragment length.

Table 2

Characteristics of the patients group studied with regard to age of onset

\begin{tabular}{|c|c|c|c|c|c|c|c|}
\hline Age group & Tumour size & & Nuclear grading & & Lymph nodes & & $\begin{array}{c}\text { Total cases } \\
\end{array}$ \\
\hline & pT1-pT2 & pT3-pT4 & Low & High & Positive & Negative & $130(100 \%)$ \\
\hline$\leq 70$ & 44 & 0 & 40 & 4 & 30 & 14 & $44(34)$ \\
\hline $71-76$ & 60 & 12 & 64 & 8 & 60 & 12 & $72(55)$ \\
\hline$\geq 76$ & 12 & 2 & 13 & 1 & 13 & 1 & $14(11)$ \\
\hline
\end{tabular}

tionally; after an AmplTaq Gold activation at $95^{\circ} \mathrm{C}$ for $10^{\prime}$, each sample with specific primers for CCND1 together with primers of human GAPDH used as internal control was subjected to 30 cycles of amplification consisting of $30 \mathrm{sec}$ of denaturation at $94^{\circ} \mathrm{C}, 30 \mathrm{sec}$ of annealing at $54^{\circ} \mathrm{C}$ and $30 \mathrm{sec}$ of extension at $72^{\circ} \mathrm{C}$. The final extension step at $72^{\circ} \mathrm{C}$ was extended to $10 \mathrm{~min}$.

The RT- PCR products amplified was carried on $2 \%$ agarose gel electrophoresis and visualized by ethidium bromide staining under an UV transilluminator.

\subsection{Statistical analysis}

Given the variability of the data and asymmetrical distribution, statistical analysis was performed considering 3 age classes determined by calculating quartiles. Age classes were: $\mathrm{E} 1=\leq 70$ years, $\mathrm{E} 2=71-76$ years, $\mathrm{E} 3=\geq 76$ years.

Spearman rank correlation was used to calculate interdependence between the variables studied. Relative Incidence (RI) and the confidence interval (CI) at $95 \%$ were estimated to evaluate the influence of each variable relative to age [26] and to indicate the range within which falls with a probability of $95 \%$ the average population from which the samples were extracted, respectively. The general model of weighted regression for qualitative and dichotomic variables allowed probability evaluation of variables changing in relation to age. Finally, a comparison was made between age classes and variables using a non-parametric statistical method, the NPC test.

\section{Results}

\subsection{Characteristics of the study population}

Tumour size, nuclear grading and lymph node positivity are outlined in Table 2.

Significant interdependences on application of the Spearman rank correlation was founded and included the relationship between the ER and the age of selected breast cancer cases $(p=0.019)$; moreover, the PR and ER expression $(p=0.000)$.

In particular, we studied the estimated risk index (RI) in relation to each molecular variable considered in three classes of age $(\mathrm{E} 1=\leq 70$ years, $\mathrm{E} 2=71-76$ years, E3 $=\geq 76$ years).

Comparing subjects belonging to the first age class (E1) against the other classes (E2-E3) for the ER expression, RI was 0.38 , indicating a prevalence of a low ER expression values for the E1 class. Further comparisons $(\mathrm{E} 2 \longrightarrow \mathrm{E} 1+\mathrm{E} 3$ and $\mathrm{E} 3 \longrightarrow \mathrm{E} 1+\mathrm{E} 2)$ showing a RI values of 1.24 and 1.41 , respectively, confirmed a prevalence in the E2 and E3 classes of high ER expression (Table 3A). Considering the expression of $\mathrm{PR}$ as the statistical variable, the incidence values regarding the first age class $(\mathrm{RI}=1.01)$ and the last age class $(\mathrm{RI}=0.95)$ show a similar behavior. A value of 1.100 in the second class shows a slight prevalence of high PR expression in this class of age (Table 3A). A strong prevalence of high values of ki-67 proliferation index was registered for the subjects from the E1 class (RI value of 1.89). In the second age class, on the other hand, IR $=0.62$ indicates a prevalence of low 
Table $3 \mathrm{~A}$

Relative Incidence (RI) and the confidence interval (CI)

\begin{tabular}{lccccccccccccc}
\hline Class & Age & $\begin{array}{c}\text { ER } \\
\text { High }\end{array}$ & $\begin{array}{c}\text { ER } \\
\text { Low }\end{array}$ & RI & CI & $\begin{array}{c}\text { PR } \\
\text { High }\end{array}$ & $\begin{array}{c}\text { PR } \\
\text { Low }\end{array}$ & RI & CI & $\begin{array}{c}\text { Ki-67 } \\
\text { High }\end{array}$ & $\begin{array}{c}\text { Ki-67 } \\
\text { Low }\end{array}$ & $\begin{array}{c}\text { RI } \\
\text { CI }\end{array}$ \\
\hline E1 & $\leq 70$ & 8 & 26 & 0.38 & $0.19-0.78$ & 10 & 24 & 1.00 & $0.53-1.90$ & 22 & 12 & 1.89 & $1.02-3.49$ \\
E2 & $71-76$ & 16 & 16 & 1.24 & $0.68-2.26$ & 10 & 22 & 1.10 & $0.57-2.10$ & 12 & 20 & 0.62 & $0.33-1.16$ \\
E3 & $\geq 76$ & 34 & 30 & 1.41 & $0.99-1.99$ & 18 & 46 & 0.95 & $0.64-1.40$ & 30 & 34 & 0.91 & $0.64-1.29$ \\
\hline
\end{tabular}

Estimated risk index regarding expression of ER, PR and ki-67 antigene variable relative to the three age classes.

Table 3B

Relative Incidence (RI) and the confidence interval (CI)

\begin{tabular}{lcccccrrrr}
\hline Class & Age & $\begin{array}{c}\text { CCND1 } \\
\text { High }\end{array}$ & $\begin{array}{c}\text { CCND1 } \\
\text { Low }\end{array}$ & RI & CI & D1 & D1 & RI \\
Low & CI \\
\hline E1 & $\leq 70$ & 6 & 28 & 0.39 & $0.17-0.88$ & 6 & 28 & 0.45 \\
E2 & $71-76$ & 12 & 20 & 1.09 & $0.59-2.03$ & 8 & 24 & 0.70 & $0.34-1.42$ \\
E3 & $\geq 76$ & 28 & 36 & 1.42 & $1.01-1.99$ & 28 & 36 & 1.63 & $1.17-2.27$ \\
\hline
\end{tabular}

Estimated risk index regarding amplification of $C C N D 1$ and expression of cyclin D1 variable relative to the three age classes.

ki-67 values. The RI value in E3 indicates, instead, a similarity in group behaviour $(\mathrm{RI}=0.91)$ as shows in Table 3A.

For CCND1 (Table 3B), the 0.39 RI value indicates the prevalence of low values in the first age class; the situation is inverted in the other classes $(\mathrm{RI}=1.09$ and $\mathrm{RI}=1.42$ ). These dates were confirmed also by RT-PCR analysis (Fig. 1), so using specific primers (Accession NCBI NM_053056.2- Table 1) the expression of $C C N D 1$ was detectable in each analyzed sample and compared with that of a constitutively expressed control gene: glyceraldehyde-3-phosphate dehydrogenase (GAPDH) because of inability to make a Real-Time RT-PCR. Amplicons were limited to $107 \mathrm{bp}$ in length because of the degraded condition of the FFPE mRNA.

With regard to the Cyclin D1 variable (Table 3B), the $\mathrm{RI}=0.45$ value, referring to the first age class indicates a prevalence of low values, the situation is reversed in the other age classes $(\mathrm{RI}=0.70$ and $\mathrm{RI}=1.63)$.

From a comparison among age classes, with the NPC test, regarding all variables studied only ki-67 differentiated the groups $(p=0.017)$; to be more precise, significant differences were seen comparing E1-E2 $(p=0.032)$ and E1-E3 $(p=0.020)$, with higher values compared to the second $(p=0.018)$ and the third age class $(p=0.016)$.

\section{Discussion}

Our study shows that there is, also in vivo, a higher demand for cyclin D1 expression and that the highest

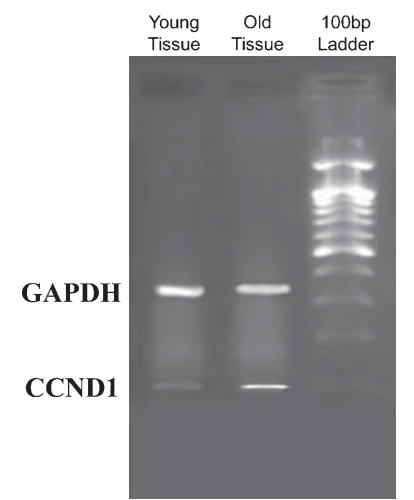

Fig. 1. 2\% Agarose gel electropherogram of RT PCR products amplified using human RNA as template, primer pairs of CCND1 and primer pairs of GAPDH as internal control. Lane 1-2 we ran an aliquot containing GAPDH and CCND1 coamplified RT-PCR products of section tumor specimens of young and old patients respectively. Lane 3 we ran a 100 bp ladder.

incidence of $C C N D 1$ amplification is seen, especially, in older age group (Fig. 2B) than younger (Fig. 2A). Molecular study shows also there are higher levels of CCND1 expression in older age group, than younger (Fig. 1). We wanted to verify if there was amplification of $C C N D 1$ also in healthy breast tissue of the patients. With the exception of one case, where there was cytoplasmtic immunohistochemical positivity (data not shown), not considered significant and classified as a negative finding by the anatomic-pathologists. There were no signs of amplification in the gene under study, nor any enhanced nuclear expression of the corresponding protein. 

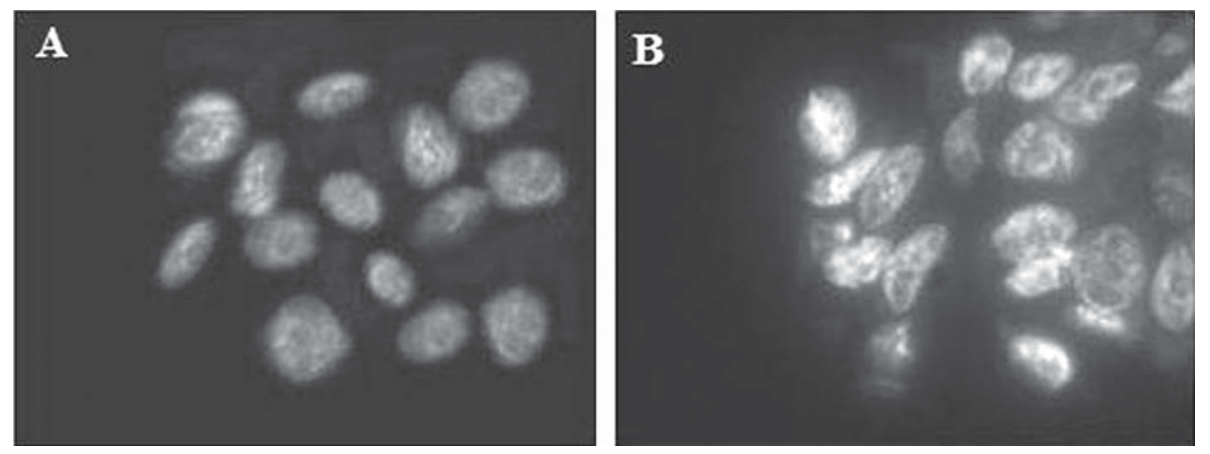

Fig. 2. Hybrydization in situ of CCND1 in tissue section of tumor specimens of older age group (B) shows the highest incidence of gene amplification than younger patients (A).

We can therefore state that enhanced cyclin D1 is exclusive to cells which have undergone a transformation process in an aged tissular microenvironment and then to underline how breast tumoral disease has emerged as an age-dependent disease. On the basis of this information we have reconsidered the molecular variables studied in relation with the patient's age and we have seen that an increase in age increases the degree of receptor expression for estrogens. In effect, the highest value was recorded in the oldest group (E3), with $\mathrm{RI}=1.41$, followed by $\mathrm{RI}=1.24$ in $\mathrm{E} 2$, with the lowest level in the youngest group E1, RI 0.38.

It is known that the aging process is a gradual hyperdifferentiation process. The breast tissue suffers this molecular and structural differentiation process; young tissue is, paradoxically, poorer in receptor expression compared to older tissue.

The degree of expression for progesterone receptors regarding age shows a decreasing trend, opposite to the trend for oestrogen receptors. The degree of expression for progesterone receptors shows a particular trend, with $\mathrm{RI}=1.01,1.10$ and $0.95 \mathrm{in} \mathrm{E} 1, \mathrm{E} 2$ and $\mathrm{E} 3$ respectively (Table $3 \mathrm{~A}$ ), suggesting that progesterone receptor expression decreases with an increase in age albeit without non-drastic changes. These data suggest a possible protective role of PR expression in the breast cancerogenesis, as reported in other papers [4-12].

Also the proliferation rate, in our study, reflects the relationship with the age variable: in group E1 $\mathrm{RI}=1.89$, while E2 and E3 have RI values of 0.62 and 0.91 respectively. There is an obvious discrepancy between the value recorded in the youngest compared to the other two groups where there is an evident reduction in the cellular reproduction capacity highlighted by histotype, grading and stage of selected cases as being equal. These results would suggest that there is a biological aggressivity age dependent. It was obvious that, with an increase in age, there was a corresponding parallel between the state of $C C N D 1$ and cyclin D1. In particular, an increasing trend of gene amplification is associated with a correspondent protein expression.

In biological and prognostic terms, it should be underlined that the proliferative axis cannot be identified in post-menopausal women, as in the corresponding younger population, with receptoral positivity for oestrogens, high proliferation rate and high expression of cyclin D1. Indeed this population of women is affected by tumors with a low proliferation rate which correlated to an increased expression of cyclin D1 and shows increased expression of oestrogen receptors.

\section{Conclusions}

The results of this study confirm the important role of Cyclin D1 in tumoral proliferation mechanisms, in the young women tumors. And above all, we show a more determining role of cyclin D1 in the hyperdifferentiation process associated with the process of cell aging, in old women tumors.

\section{References}

[1] M. Abramovitz, M. Ordanic-Kodani, Y. Wang, et al., Optimization of RNA extraction from FFPE Tissues for expression profiling in the DASL assay, BioTechniques 44 (2008), $417-423$.

[2] P. Atadja, H. Wong, C. Veillete, et al., Overexpression of Cyclin D1 blocks proliferation of normal diploid fibroblasts, Exp Cell Res 217 (1995), 205-216; PMID: 7698220. 
[3] M.F. Buckley, K.J. Sweeney, J.A. Hamilton, et al., Expression and amplification of cyclin genes in human breast cancer, Oncogene 8 (1993), 2127-2133; PMID: 8336939.

[4] R.B. Clarke, Steroid receptors and proliferation in the human breast, Steroids 68 (2003), 789-794; PMID: 14667969.

[5] Y. Dai, T.E. Hamm, P. Dent, et al., Cyclin D1 overexpression increases the susceptibility of human U266 myeloma cells to CDK inhibitors through a process involving p130-, p107and E2F-dependent S phase entry, Cell Cycle 5(4) (2006), 437-446; PMID: 16479154.

[6] S. Elsheikh, A.R. Green, M.A. Aleskandarany, et al., CCND1 amplification and cyclin D1 expression in breast cancer and their relation with proteomic subgroups and patient outcome, Breast Cancer Res Treat 109(2) (2008), 325-335; PMID: 17653856.

[7] A.R. Frost, D. Sparks and W.E. Grizzle, Methods of antigen recovery vary in their usefulness in unmasking specific antigens in immunohistochemistry, Appl Immunohistochem Mol Morphol 8 (2000), 236-243; PMID: 10981877.

[8] J. Fukami, K. Anno, K. Ueda, et al., Enhanced expression of cyclin D1 in senescent human fibroblasts, Mech Ageing Dev 81 (1995), 139-157; PMID: 8569279.

[9] C.E. Gillett, A.H. Lee, R.R. Millis, et al., Cyclin D1 and associated proteins in mammary ductal carcinoma in situ and atypical ductal hyperplasia, J Pathol 184(4) (1998), 396-400; PMID: 9664905.

[10] I. Hadzisejdić, E. Mustać, N. Jonjić, et al., Nuclear EGFR in ductal invasive breast cancer: Correlation with cyclin-D1 and prognosis, Mod Pathol 23(3) (2010), 392-403; PMID: 19201737.

[11] P.W. Hinds, S.F. Dowdy, E.N. Eaton, et al., Function of a human cyclin gene as an oncogene, Proc Natl Acad Sci U S A 91(2) (1994), 709-713; PMID: 8290586.

[12] Ke-Da Yu, Guang-Yu Liu, Di Gen-Hong Di, et al., Progesterone receptor status provides predictive value for adjuvant endocrine therapy in older estrogen receptor-positive breast cancer patients, The Breast 16(3) (2007), 307-315; PMID: 17293115 .

[13] L. Krecsak, T. Micsik, G. Kiszler, et al., Technical note on the validation of a semi-automated image analysis software application for estrogen and progesterone receptor detection in breast cancer, Diagn Pathol 6(1) (2011), [Epub ahead of print]; PMID: 21244664.

[14] A. Lebeau, A. Unholzer, G. Amann, et al., EGFR, HER-2/neu, cyclin D1, p21 and p53 in correlation to cell proliferation and steroid hormone receptor status in ductal carcinoma in situ of the breast, Breast Cancer Res Treat 79(2) (2003), 187-198; PMID: 12825853.

[15] S. Lehn, N.P. Tobin, P. Berglund, et al., Down-regulation of the oncogene cyclin D1 increases migratory capacity in breast cancer and is linked to unfavorable prognostic features, $\mathrm{Am} \mathrm{J}$ Pathol 177(6) (2010), 2886-2897; PMID: 20971731.
[16] S.Y. Lin, K. Makino, W. Xia, et al., Nuclear localization of EGF receptor and its potential new role as a transcription factor, $\mathrm{Nat}$ Cell Biol 3(9) (2001), 802-808; PMID: 11533659.

[17] N.M. Malara, A. Leotta, A. Sidoti, et al. Ageing, hormonal behaviour and cyclin D1 in ductal breast carcinomas, The Breast 15 (2006), 81-89; PMID: 16473739.

[18] N. Malara, D. Focà, F. Casadonte, et al., Simultaneous inhibition of the constitutively activated nuclear factor kappaB and of the interleukin-6 pathways is necessary and sufficient to completely overcome apoptosis resistance of human U266 myeloma cells, Cell Cycle 7(20) (2008), 3235-3245; PMID: 18931595.

[19] N. Masuda, T. Ohnishi, S. Kawamoto, et al., Analysis of chemical modification of RNA from formalin-fixed samples and optimization of molecular biology applications for such samples, NUC Acids Res 27(22) (1999), 4436-4443; PMID: 10536153.

[20] H. Ni, M. Ergin, Q. Huang, et al., Analysis of expression of nuclear factor kappa B (NF-kappa B) in multiple myeloma: Downregulation of NF-kappa B induces apoptosis, Br J Haematol 115(2) (2001), 279-286; PMID: 11703322.

[21] P.G. Roy and A.M. Thompson, Cyclin D1 and breast cancer, The Breast 15 (2006), 718-727; PMID: 16675218.

[22] P.G. Roy, N. Pratt, C.A. Purdie, et al., High CCND1 amplification identifies a group of poor prognosis women with estrogen receptor positive breast cancer, Int J Cancer 127(2) (2010), 355-360; PMID: 19904758.

[23] D.W. Stacey, Cyclin D1 serves as a cell cycle regulatory switch in actively proliferating cells, Curr Opin Cell Biol 15 (2003), 158-163; PMID: 12648671.

[24] K. Subik, J.F. Lee, L. Baxter, et al., The Expression Patterns of ER, PR, HER2, CK5/6, EGFR, Ki-67 and AR by Immunohistochemical analysis in breast cancer cell lines, Breast Cancer: Basic and Clinical Research 4 (2010), 35-41; PMID: 20697531.

[25] L.I. Talley, W.E. Grizzle, J.W. Waterbor, et al., Hormone receptors and proliferation in breast carcinomas of equivalent histologic grades in pre- and postmenopausal women, Int $J$ Cancer 98 (2002), 118-127; PMID: 11857395.

[26] D. Urban, R. Myers, U. Manne, et al. Evaluation of biomarker modulation by fenretinide in prostate cancer patients, Eur Urol 35(5-6) (1999), 429-438; PMID: 10325501.

[27] C.B. Vos, N.T. Ter Haar, J.L. Peterse, et al., Cyclin D1 gene amplification and overexpression are present in ductal carcinoma in situ of the breast, J Pathol 187(3) (1999), 279-284; PMID:10398079.

[28] R.M. Zwijsen, R. Klompmaker, E.B. Wientjens, et al., Cyclin D1 triggers autonomous growth of breast cancer cells by governing cell cycle exit, Mol Cell Biol 16(6) (1996), 2254-2260. PMID: 8649362. 


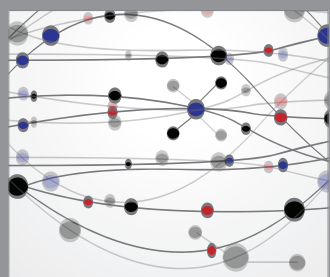

The Scientific World Journal
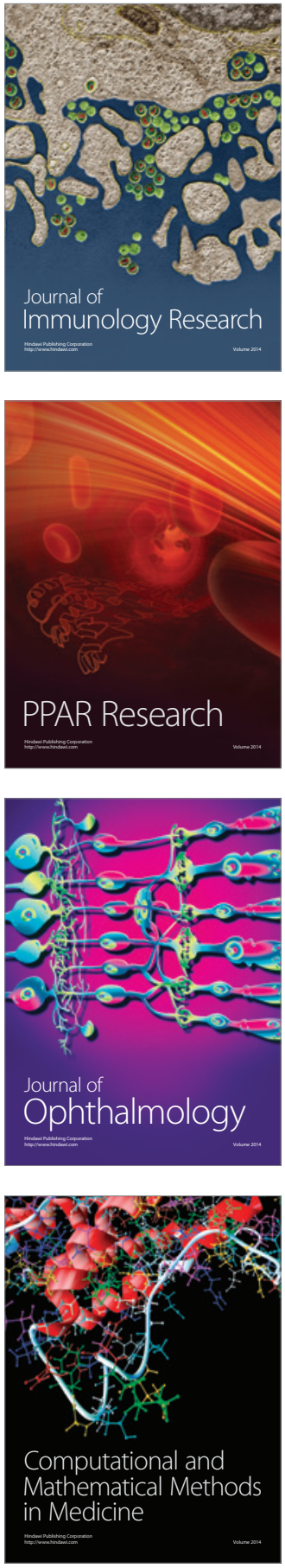

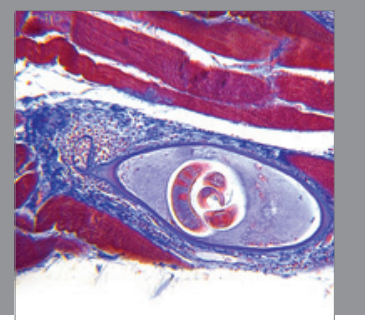

Gastroenterology

Research and Practice
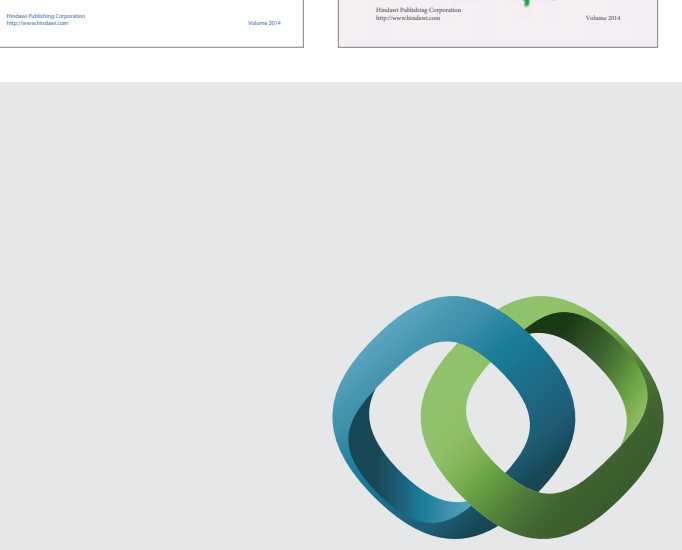

\section{Hindawi}

Submit your manuscripts at

http://www.hindawi.com
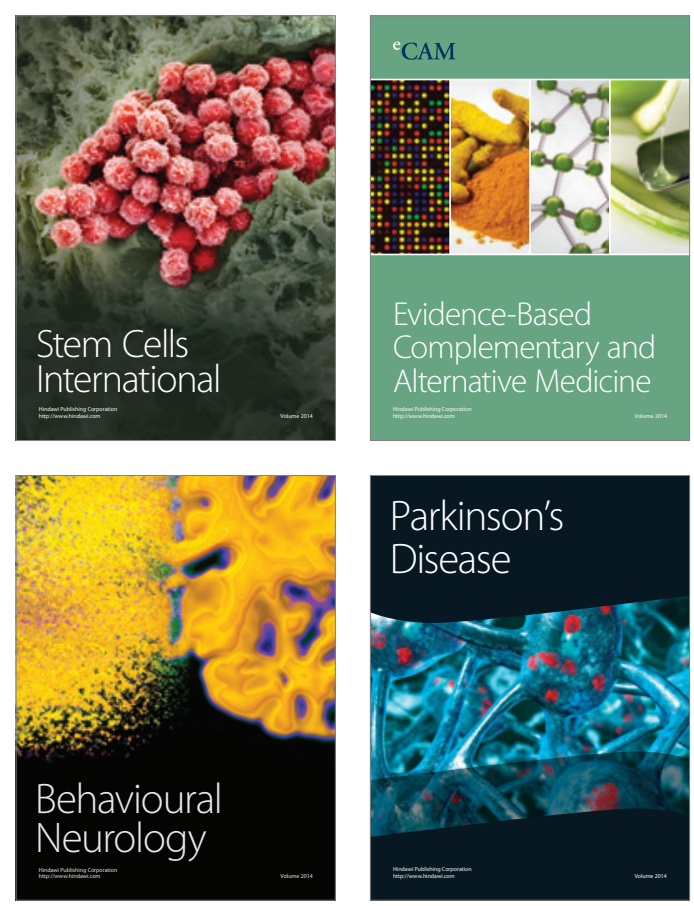

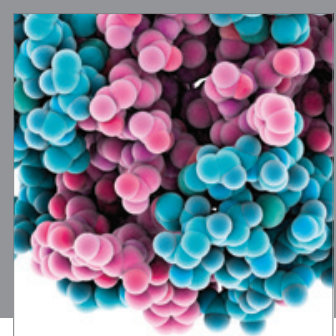

Journal of
Diabetes Research

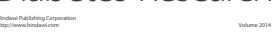

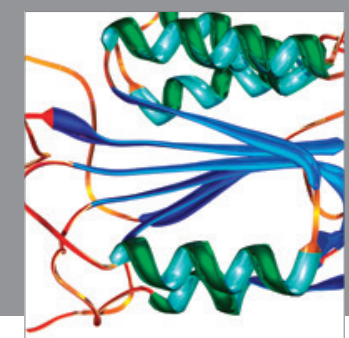

Disease Markers
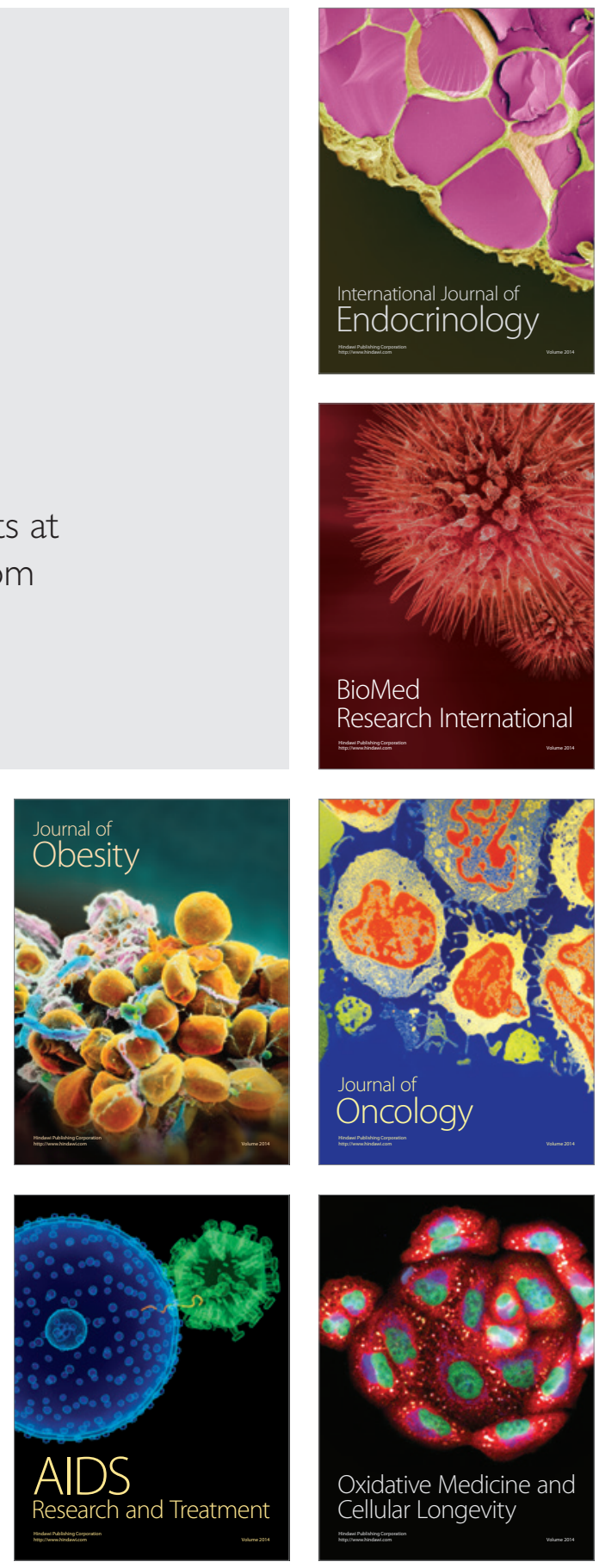